Cita: Salgado-López, J.I.; Sánchez-Molina, J.A. (2021). Contacto y emociones en la enseñanza de deportes sociomotores de colaboración-oposición a futuros docentes de educación física. Cuadernos de Psicología del Deporte, 21(3), 62-82

\title{
Contacto y emociones en la enseñanza de deportes sociomotores de colaboración-oposición a futuros docentes de educación física
}

\section{Contact and emotions in teaching sociomotor sports of collaboration opposition to future physical education teachers}

\section{Contacto e emoções no ensino de desportos sóciomotores de colaboração- oposição a futuros docentes de educação física}

\author{
Salgado-López, J.I. ${ }^{1}$, Sánchez-Molina, J.A. ${ }^{2}$ \\ ${ }^{1}$ Grupo de Estudios Praxiológicos Independientes (España); ${ }^{2}$ Universidade da Coruña (España)
}

\begin{abstract}
RESUMEN (150 palabras) (mismo orden que títulos)
Partiendo de la conceptualización de los problemas afectivos derivados del contacto (PADC) estudiamos su influencia en el aprendizaje de Rugby, Balonmano y Voleibol. El trabajo, desarrollado en el contexto universitario $(\mathrm{n}=16)$, se aborda dentro del paradigma cualitativo, mediante el análisis de contenido y con el apoyo de estrategias cuantitativas, siguiendo los Métodos Mixtos. El estudio prospectivo de los datos permitió describir la realidad a estudiar y el refinamiento de la metodología, centrada en el método de análisis de diarios con entrevista sobre los diarios, con el apoyo de herramientas informáticas de análisis cualitativo (Nvivo). Los resultados muestran la existencia de PADC y su influencia negativa en el aprendizaje de tareas motrices de los deportes estudiados. Las emociones que suscitan la aparición de estos problemas están fundamentalmente relacionadas con el miedo, aunque también con la ansiedad y/o la vergüenza. Además, se describen cuáles son los tipos de contactos que generan esos problemas. Igualmente, se concretan 29 factores que podrían ser valorados para disminuir la aparición de los PADC en procesos de enseñanza-aprendizaje de tareas motrices que impliquen contacto. La importancia de cada uno de estos factores varía en función del tipo de contacto que requiera la tarea motriz.
\end{abstract}

Palabras clave: problemas afectivos derivados del contacto; miedo al contacto físico; miedo a la caída; miedo al balón; vergüenza.

ABSTRACT (150 words) (same order that title)

From the conceptualization of emotional problems related to contact (EPRC), we study its influence in the learning of Rugby, Handball and Volleyball. This research, developed at the university sphere $(n=16)$, is framed within qualitative framework through the analysis of content assisted with quantitative strategies (Mixed Methods). The prospective study of the data allowed the description of the reality in study and the refinement in methodology. So, the method focused on the analysis of diaries with interviews about them with the support of computer tools of qualitative analysis (NVivo). The results show the existence of EPRC and its negative influence in the learning of motor tasks of the aforementioned sports. The emotions that facilitate the appearance of these problems are fundamentally related to fear, but also to anxiety or shame. In addition, the types of contacts that generate these problems are described. Furthermore, there were specified 29 factors that could be considerated to decrease the 


\section{Gestión emocional en futuros docentes de educación física}

appearance of EPRCs in contact motor tasks teaching-learning processes. The importance of each of these factors varies depending on the type of contact that the motor task requires.

Keywords: emotional problems related to contact; fear of physical contact; fear of falling; fear of the ball; shame.

RESUMO (1500 palavras) (mesma ordem como títulos)

Partindo da conceituação de problemas afetivos derivados do contacto (PADC), estudamos sua influência na aprendizagem de Rugby, Handebol e Voleibol. O trabalho, desenvolvido no contexto universitário ( $\mathrm{n}=16)$, é abordado dentro do paradigma qualitativo, através do método de análise de conteúdo e com o apoio de estratégias quantitativas, seguindo os Métodos Mistos. $\mathrm{O}$ estudo prospetivo dos dados permitiu descrever a realidade a ser estudada e o aprimoramento da metodologia, centrada no método de análise de diários com entrevista sobre os diários, com o apoio duma ferramenta computacional de análise qualitativa (Nvivo). Os resultados mostram a existência do PADC e sua influência negativa na aprendizagem de tarefas motoras dos desportos observados. As emoções produtoras desses problemas estão fundamentalmente relacionadas ao medo, mas também à ansiedade ou vergonha. Além disso, são descritos os tipos de contactos que geram esses problemas. Da mesma forma, foram especificados 29 fatores que poderiam ser avaliados para diminuir a aparência dos PADCs nos processos de ensino-aprendizagem de tarefas motoras que envolvem contacto. A importância de cada um desses fatores varia de acordo com o tipo de contacto que a tarefa motora exige

Palavras chave: problemas afetivos ligados ao contacto; aversão ao contacto corporal; medo de cair; medo da bola; vergonha.

\section{INTRODUCCIÓN}

El estudio de las emociones dentro de la Educación Física (EF) ha despertado gran interés investigador a lo largo de esta última década. Ahora bien, como se recoge en la revisión de Mujica-Johnson, OrellanaArduiz y Concha-López (2017), los trabajos publicados se centran, fundamentalmente, en la descripción de la vivencia emocional suscitada por las tareas motrices y cómo esta afecta al bienestar de los implicados en las clases de EF. Además de estos, caben resaltar los estudios recogidos en la revisión sistemática de Martínez-Martínez y ValeroValenzuela (2019) por su proximidad a la población de este trabajo, aunque con las mismas características que los anteriores. También por proximidad, debemos incluir un trabajo posterior de Mujica-Johnson y Jiménez (2019) donde se estudian las emociones vivenciadas por estudiantes universitarios de una asignatura centrada en la enseñanza de un deporte sociomotor concreto, el baloncesto. Ahora bien, al igual que en la primera revisión citada, todos ellos se centran en la descripción de la vivencia emocional, dejando a un lado su influencia en el aprendizaje motor de los estudiantes o en las adaptaciones didácticas que serían necesarias a la hora de abordar la enseñanza de las tareas motrices implicadas.
El presente trabajo aborda la cuestión emocional vinculada con los contactos producidos en los procesos de enseñanza de deportes sociomotrices de colaboración-oposición y su relación con el aprendizaje motor. El punto del que partimos surge de una serie de preguntas sencillas de formular pero difíciles de responder con rigor, como son: ¿por qué a unas personas les resulta muy molesto entrar en contacto con otras?; y, al contrario, ¿por qué a algunas les resulta tan fácil? ¿Cómo influye la facilidad o la dificultad de entrar en contacto con otros individuos o cosas en los procesos de enseñanza-aprendizaje de prácticas motrices?

En 1959, Hall (2003) trató ya la importancia del uso del espacio por el ser humano. A él le siguieron infinidad de autores que tomaron como base sus trabajos. Ahora bien, parece claro que, de manera estricta, el contacto no está solo relacionado con las interacciones entre personas. Centrándonos en EF, son pocos los autores que han centrado su atención en el estudio del contacto y de los problemas que este presenta. Menos aún han sido los que, desde un punto de vista más general, han tenido en cuenta también los contactos establecidos entre un individuo y el suelo y/o los objetos, como puede ser un móvil (SalgadoLópez, 2020). Estos problemas relacionados con el contacto son fácilmente visibles en las prácticas 


\section{Salgado-López, J.I., Sánchez-Molina, J.A.}

motrices, tanto en deportes institucionalizados (Canales-Lacruz y Casedas-Gerez, 2018; CanalesLacruz y Pina-Blanco, 2014; Autor, 2004a y b; Autor, 2005; Salgado-López, 2007; Salgado-López, 2014) como también en otro tipo de prácticas tales como las expresivas (Canales-Lacruz, 2006; Canales-Lacruz y Rey-Cao, 2014; Turrán Eguren, 2011) o incluso las introyectivas (Rovira, 2010). De hecho, para todos estos autores, las conductas de evitación o búsqueda del contacto se aprecian claramente en los procesos de enseñanza-aprendizaje de esas prácticas.

El problema en la iniciación deportiva puede ser, a nuestro entender, más profundo, tanto si es específica de un deporte concreto como si está integrada en algún programa de EF escolar o, como en nuestro caso, universitario. Así, como veremos en el desarrollo del trabajo, estas dificultades asociadas al contacto son de diferentes tipos, según quién o qué intervenga y pueden representar una fuente de frustraciones $y / u$ obstáculos en el aprendizaje y evolución de un individuo dentro de una práctica motriz concreta, entorpeciendo al mismo tiempo la evolución de su motricidad. Pese a esta complejidad, o precisamente por ella, no se encuentran en la literatura específica más que algunas referencias a estos tipos de problemas desde la óptica de la praxis docente y, solo en contadas ocasiones, aparece alguna propuesta para superarlos, a modo de receta, en situaciones concretas (SalgadoLópez, 2020). Este es el caso, por ejemplo, del placaje en rugby (Collinet, 2000; Corless, 1995; Usero Martín, 1993), los lanzamientos desde el extremo en caída en balonmano (Torres Tobío, 1998) o las planchas en voleibol (Gutiérrez Santiago y Cancela Carral, 2004). Es más, muchas de estas propuestas presentan características similares, que podrían ser sistematizadas para otros tipos de tareas motrices similares (Salgado-López, Eslava Oriol, Montes Lasheras y Mariño Pego, 2003).

Así pues, una de las características del objeto de estudio que abordamos es su indefinición a nivel científico, a pesar de su amplia aceptación y constatación a nivel empírico. En concreto, resulta común encontrar entre la bibliografía profesional, entre otros, los términos de: miedo al contacto al aprender un golpeo en voleibol (Bonnefoy, Lahuppe y Né, 2000); miedo al balón en el aprendizaje de un blocaje en balonmano (Aguilar Aguilar, 2012), de acciones técnicas de fútbol (Peitersen, 2007) o de voleibol (Drauchke, Schulz y Utz, 2002); miedo a la caída, tanto en voleibol (Gutiérrez Santiago y Cancela Carral, 2004), como en gimnasia artística (Christina y Corcos, 1988); e, igualmente, es común la expresión miedo al contacto para referirse a las emociones no placenteras vinculadas con contacto físico entre personas (Troya Montañez y Cuéllar Moreno, 2008).

Desde nuestra óptica, la dificultad de definición del objeto de estudio es fruto de la naturaleza pluridimensional del problema (Figura 1) que, a su vez, determina las dimensiones del mismo. Esto nos lleva a tener en cuenta, por un lado, los aspectos relacionados con el mantenimiento de la integridad física, que podríamos asociar con el miedo a lesionarse; y, por otro, los aspectos asociados a la comunicación y a ciertos aspectos psico-morales que pudieran existir en función de la cultura en la que esté inserto el sujeto, como la vergüenza, el rubor o el asco, Además, entre ambos, consideramos que existe otra dimensión de orden filogenético relacionada con el concepto de territorialidad (Hall, 1989). Todo ello enmarcaría las llamadas esferas o espacios personales. Este concepto, definido por Hall (2003) a mediados del siglo pasado, se corresponde con el uso social que hacemos del espacio y ha sido ampliamente aceptado y/o adaptado por otros autores (Bernard, 1985; Davis, 1987; Descamps 1990; Fast, 1994; Hernández Moreno, 1994; Montagu y Matson, 1989; Pease y Pease, 2006; Sommer, 1974).

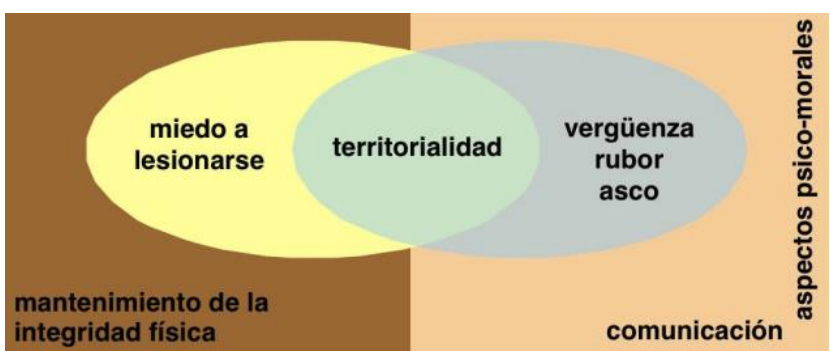

Figura 1. Dimensiones del objeto de estudio

A esa dificultad de definición del objeto de estudio se suma la multiplicidad de términos existente, lo que complica la propia conceptualización del concepto. Así, términos idénticos parecen identificar ideas distintas (Salgado-López, 2020). Por ejemplo, miedo al contacto físico muestra relación con un aspecto comunicativo o social del contacto y, al mismo tiempo, con el mantenimiento de la integridad física del individuo; este mismo significado en francés lo 


\section{Gestión emocional en futuros docentes de educación física}

adquiere problèmes affectifs liés au contact, referido a las colisiones tanto entre sujetos como con el suelo; y, de forma similar, en inglés, fear of injury, aunque este también pueda tener un significado más general asociado al miedo a lesionarse por cualquier razón.

Por todo ello, se hace necesario detenernos en la conceptualización de los problemas afectivos derivados del contacto (PADC). Estos problemas están relacionados con una reacción emocional negativa que influye en la conducta motriz de un sujeto ya sea al poner en compromiso su integridad física, como puede ser en el caso de un lanzamiento en caída en balonmano; o bien, al entrar en juego aspectos culturales de orden psico-moral, como es el caso de los contactos socialmente no admitidos en determinadas zonas del cuerpo, como se da en el agarre de segunda línea en rugby.

Si focalizamos la atención en la visión centrada en el mantenimiento de la integridad física, la cuestión se complica más. Así, las distintas fuentes del contacto, esto es, otro individuo, un móvil o el suelo, desencadenarán problemas afectivos distintos (Collinet, 2000; Usero Martín, 1993). Por su parte, señalar que no se han encontrado referencias sobre los aspectos psico-morales en la bibliografía deportiva.

Relacionando estos tres tipos de contactos, con las dimensiones del objeto de estudio vistas, obtenemos una visión completa del concepto al que nos estamos refiriendo (Figura 2). Así, los contactos entre individuos podrían generar problemas en función del mantenimiento de la integridad física; pero también desde el punto de vista de los aspectos relacionados con la territorialidad o con cuestiones psico-morales, como la vergüenza o rubor y/o el asco. Por su parte, el suelo tendría relación solo con los aspectos relacionados con el mantenimiento de la integridad física y los aspectos psico-morales antes citados, ya que la territorialidad se centra en el uso del espacio entre individuos. Junto con estos, el contacto con objetos sólo parece relacionarse con el mantenimiento de la integridad física.

En función de lo anterior y dado la falta de una definición que agrupe claramente el concepto, seguimos la aportada por Salgado-López (2014): los PADC son dificultades de orden didáctico que influyen negativamente en el aprendizaje motor de un individuo, debido a una reacción emocional asociada a una acción motriz que implica entrar en contacto con otros individuos, objetos y/o suelo, y que, además, interfiere en la fase de toma de decisiones, pudiendo dar como resultado una conducta motriz desajustada.

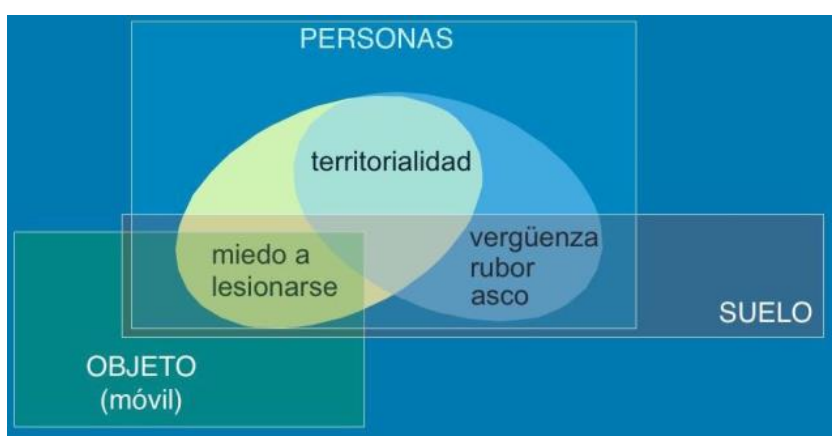

Figura 2. Relación entre las distintas dimensiones de PADC y las fuentes originadoras de los contactos

Con todo ello, los objetivos que han guiado esta investigación han sido: a) describir la vivencia emocional asociada al contacto percibida por los estudiantes universitarios durante un proceso de enseñanza/aprendizaje de deportes sociomotores de colaboración-oposición, en los casos concretos de rugby, balonmano y voleibol; b) concretar qué tipos de contactos pueden producir la aparición de PADC en la enseñanza de deportes sociomotores ya mencionados; c) describir las influencias que esas emociones producen en el aprendizaje de tareas motrices de enseñanza de los citados deportes; d) describir cuáles son los factores fundamentales que se relacionan con la aparición de PADC en las circunstancias de enseñanza anteriores.

\section{MÉTODO}

\section{Diseño de investigación}

El presente trabajo se diseñó como Estudio de Casos, al considerar que era el que mejor se adaptaba a nuestras necesidades en función del contexto y del número de sujetos participantes. Este diseño tiene un carácter no experimental de estrategia descriptiva (Ato, López y Benavente, 2013). Se inserta, dentro del paradigma interpretativo, en los Métodos Mixtos, aunque que para algunos podría considerarse un paradigma en sí mismo (Anguera, Portell, ChacónMoscoso, y Sanduvete-Chaves, 2018). Bajo la óptica de la metodología observacional, en tanto que observación indirecta (Anguera et al., 2018), se trata de un diseño nomotético, en seguimiento y 


\section{Salgado-López, J.I., Sánchez-Molina, J.A.}

multidimensional (Anguera, Blanco Villaseñor, Hernández Mendo y Losada, 2011). Dentro de los Metodos Mixtos, el estudio es de tipo CUAL/CUAL (Castañer, Camerino, y Anguera, 2013). Es decir, los datos cualitativos son preeminentes en las dos herramientas a utilizar (diario y entrevista). En este sentido, los datos cuantitativos son un apoyo descriptivo de los anteriores.

El método, se centró en el denominado método de diarios con entrevistas sobre el diario (Plummer, 1989). Así, utilizamos el diario como herramienta base para la extracción de los datos, mediante el análisis de contenido (Bardin, 1996) y la entrevista como medio de contraste.

\section{Participantes}

El estudio se realizó con dos grupos de estudiantes, de otros tantos cursos académicos distintos y consecutivos, dentro de la asignatura de Deportes de Equipo de una titulación superior española con competencias para la docencia de EF escolar. Su edad oscilaba de entre 19 y 26 años $\left(M_{\text {edad }}=21,5 ; S D=2,06\right)$. La elaboración de la muestra se realizó por muestreo por conveniencia no probabilístico. Los criterios de selección fueron: estar matriculados en la asignatura antes citada, entregar los diarios de sensaciones (herramienta presentada más adelante) y participar en la entrevista sobre el citado diario.

El número de participantes se concretó en un total de 16 sujetos (10 hombres y seis mujeres), acorde a otros estudios con una metodología similar (Campo, Mellalieu, Ferrand, Martinent, y Rosnet, 2012). Los estudiantes dieron su consentimiento informado para la realización del estudio, manteniéndose su anonimato mediante el uso de "alias" (Flick, 2015).

Para finalizar, es necesario señalar que el profesor de la asignatura desempeñó también el rol de investigador, participando en todas las fases del trabajo.

\section{Instrumentos}

El instrumento fundamental del que se extrajeron los datos es el que hemos denominado diario de sensaciones, elaborado por los participantes. Esta denominación emplea el término sensaciones como sinónimo de impresiones y en él se pedía que recogieran las sensaciones, emociones y sentimientos que les suscitaban las tareas motrices desarrolladas. El uso indistinto de estos tres términos obedece a una cuestión práctica, ya que la utilización del término emociones producía problemas de comprensión acerca del sentido que se pretendía dar al diario. Es más, usar este término nos obligaría a realizar una fase previa de educación emocional como han realizado otros estudios (Jaqueira, Lavega, Lagardera, Araújo y Rodrigues, 2014; Lavega, Costes y Prat, 2015; Lavega, Filella, Lagardera, Mateu y Ochoa, 2013; Rovira, López-Ros, Lagardera, Lavega y March, 2014). Ahora bien, dado al carácter exploratorio del estudio, esta fase formativa podría condicionar los resultados obtenidos dirigiendo la atención hacia ciertas emociones en detrimento de otras, lo que reduciría la calidad del dato. Además de estas cuestiones, para la elaboración del diario únicamente se les indicó, a comienzo de curso, ciertos aspectos formales (formato digital .doc) con el objetivo de facilitar su análisis mediante software.

Además, se utilizó la entrevista como contraste a los diarios, para resolver dudas en cuanto a la codificación de las unidades textuales a analizar. Esta entrevista fue de tipo verbal, individual y no estandarizada, basándose en un guion previo, buscando con ello un diálogo fluido con el sujeto (Heinemann, 2003). La incorporación de esta herramienta se produjo después de constatar, mediante un estudio piloto previo, la dificultad de realizar una codificación con criterios altos de credibilidad incluso con dos codificadores (Autor, 2004a, 2004b y 2005). Por ello, preferimos preguntar directamente a los autores de los textos en los casos que nos asaltaban dudas del significado real de algún extracto que pudiera resultar interesante al objeto de la investigación. Las entrevistas fueron grabadas en un sistema de audio y luego transcritas para su análisis.

Por último, también se utilizó una hoja de registro (ficha de clase) en la que, además de los datos personales de los estudiantes necesarios para la docencia, se les preguntaba por sus experiencias motrices previas antes del comienzo de la asignatura. Estos datos se utilizaron únicamente de forma exploratoria para facilitar el diseño de las preguntas sobre este aspecto en la entrevista. Es por ello que no se llevó a cabo un análisis directo de los datos extraídos mediante este instrumento. 


\section{Gestión emocional en futuros docentes de educación física}

\section{Análisis de los datos}

Para la extracción de los datos se realizó un análisis de contenido de los diarios y de las entrevistas de los estudiantes, tanto desde el punto de vista textual, dentro del paradigma cualitativo, como frecuencial, de corte más cuantitativo. El proceso de codificación consistió en asociar extractos de texto (unidades textuales) a un sistema de categorías. Esta codificación se llevó a cabo por duplicado y por un solo investigador, con el suficiente margen temporal como para provocar su olvido por el codificador, tal como establece Anguera (1997). De esta manera, se realizó una primera codificación aproximativa tras la entrega de los diarios, siendo revisada cinco meses después. Tras ello, se resolvieron las dudas existentes mediante una entrevista al autor o autora del diario a analizar. El análisis de contenido de los diarios y entrevistas (documentos primarios y secundarios respectivamente) se realizó mediante un programa informático de apoyo para investigación cualitativa (Nvivo 7 y 12) y se organizó en un archivo único (Unidad Hermenéutica, Figura 3). En ese archivo se almacenaron todos los documentos, la codificación y las anotaciones surgidas durante el proceso. Por último, una vez realizada la codificación, se procedió a una última revisión de la codificación introducida en el citado programa.

Para realizar el análisis, tanto a nivel cualitativo como cuantitativo, se establecieron inicialmente dos sistemas taxonómicos: uno principal de categorías, cerrado y de tipo deductivo, basado en los tipos de contactos posibles; $\mathrm{y}$, otro secundario conformado por formatos de campo, de tipo inductivo (Anguera, 1997; Hernández Mendo y Molina Macías, 2002). Este segundo sistema era de carácter abierto y no jerarquizado, centrado en los factores que influían en la aparición de los PADC que los sujetos identificaban a lo largo de los extractos de su diario, presentados en la entrevista para su contrastación. En tanto que inductivo, fue construido al mismo tiempo que se realizaba la codificación. Una vez terminada dicha codificación, fue necesario revisarla de nuevo ya que ciertas subcategorías no habían sido especificadas en el momento del análisis de los primeros documentos. Tenemos que señalar también que la categorización principal debió ser aumentada de forma inductiva con un formato de campo relacionado con la dimensión social de los contactos suaves (explicada a continuación). Esto fue debido a que su concreción se realizó durante el proceso de proceso de revisión al no hallarse referencias a ella en la bibliografía y después de debatirlo con otros investigadores ajenos al proyecto, pero expertos en la metodología. Es por ello, que este sistema presenta finalmente un carácter mixto deductivo-inductivo.

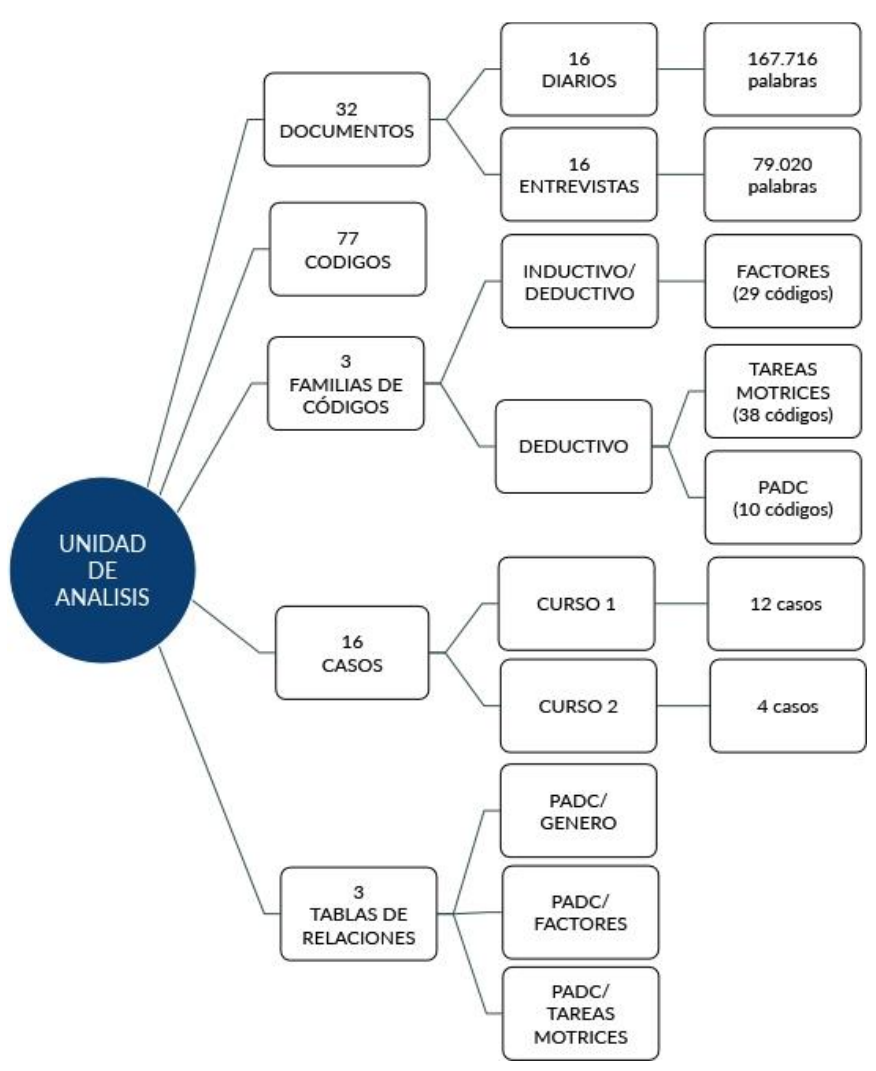

Figura 3. Componentes de la Unidad Hermenéutica.

En cuanto al sistema de categorías principal, en el estudio piloto antes citado utilizamos las descritas por Salgado-López et al. (2003). En él se tomaba como criterio los tipos de contactos que podían generar las emociones causantes de PADC en las situaciones motrices a analizar. Ahora bien, tras los resultados del estudio piloto, se decidió incrementar las categorías de análisis utilizadas (Tabla 1), diferenciando dos dimensiones: una personal, en base a la categorización ya existente, donde la emoción suscitada se relaciona con el propio individuo; y, otra social, de carácter más empático, en la que la emoción surgía al asociar la propia acción motriz con las consecuencias para otra persona 


\section{Salgado-López, J.I., Sánchez-Molina, J.A.}

Tabla 1. Sistema de observación utilizado en la codificación principal

\begin{tabular}{|c|c|c|c|}
\hline Dimensión & Categoría & Subcategoría & Ejemplo \\
\hline \multirow[t]{6}{*}{ Personal } & $\begin{array}{l}\text { contactos } \\
\text { interpersonales }\end{array}$ & $\begin{array}{l}\text { bruscos: emociones surgidas por contactos } \\
\text { violentos. }\end{array}$ & $\begin{array}{l}\text { placaje en rugby. } \\
\text { bloqueo en balonmano. }\end{array}$ \\
\hline & & $\begin{array}{l}\text { suaves: emociones suscitadas por contactos donde } \\
\text { el componente comunicativo es fundamental. }\end{array}$ & $\begin{array}{l}\text { contactos dentro de una melé de } \\
\text { rugby, sobre todo los agarres de la } \\
\text { segunda a la primera línea. }\end{array}$ \\
\hline & $\begin{array}{l}\text { contactos } \\
\text { cuerpo-suelo }\end{array}$ & $\begin{array}{l}\text { caídas involuntarias: emociones asociadas a } \\
\text { contactos con el suelo en los que el sujeto no } \\
\text { decide sobre su realización. }\end{array}$ & ser placado por otro en rugby. \\
\hline & & $\begin{array}{l}\text { caídas voluntarias: emociones asociadas a } \\
\text { contactos con el suelo en los que el sujeto toma la } \\
\text { decisión de realizarlas. }\end{array}$ & $\begin{array}{l}\text { placar en rugby. } \\
\text { planchas en voleibol. }\end{array}$ \\
\hline & $\begin{array}{l}\text { contactos } \\
\text { cuerpo-objeto }\end{array}$ & $\begin{array}{l}\text { recepciones: emociones suscitadas por contactos } \\
\text { vinculados a recogidas voluntarias de un objeto } \\
\text { lanzado. }\end{array}$ & al aprender un pase realizado por otro. \\
\hline & & $\begin{array}{l}\text { golpeos: emociones asociadas a contactos con un } \\
\text { objeto sin que exista intención de retenerlo, sino } \\
\text { simplemente de desviar su trayectoria. }\end{array}$ & $\begin{array}{l}\text { en voleibol al desviar el balón lanzado } \\
\text { por otro, ya sea pase o recepción. }\end{array}$ \\
\hline \multirow[t]{4}{*}{ Social } & $\begin{array}{l}\text { contactos } \\
\text { interpersonales }\end{array}$ & $\begin{array}{l}\text { bruscos: emociones asociadas a la consciencia de } \\
\text { un posible daño a otra persona al ejecutar una tarea } \\
\text { motriz. }\end{array}$ & $\begin{array}{l}\text { en rugby, si el portador del balón se } \\
\text { frena antes del impacto con el otro } \\
\text { para evitar derribarlo. }\end{array}$ \\
\hline & & $\begin{array}{l}\text { suaves: emociones relacionadas con la generación } \\
\text { de contactos posiblemente violentos desde un } \\
\text { punto de vista moral a otra persona implicada en } \\
\text { la acción motriz. }\end{array}$ & $\begin{array}{l}\text { En rugby-imagen evitar tocar por } \\
\text { debajo de la cintura a jugadores de } \\
\text { género contrario para evitar } \\
\text { suspicacias. }\end{array}$ \\
\hline & $\begin{array}{l}\text { contactos } \\
\text { cuerpo-objeto }\end{array}$ & $\begin{array}{l}\text { pases: emociones vivenciadas por un sujeto } \\
\text { (pasador) en base a la posibilidad de causar daño } \\
\text { a otra persona al realizar un pase. Debe producirse } \\
\text { una recepción controlada por la otra persona } \\
\text { (receptor). }\end{array}$ & $\begin{array}{l}\text { realizar pases excesivamente flojos, } \\
\text { para evitar posibles lesiones a } \\
\text { compañeros. }\end{array}$ \\
\hline & & $\begin{array}{l}\text { golpeos: emociones vivenciadas por un sujeto que } \\
\text { ejecuta un lanzamiento o golpeo de un móvil, ante } \\
\text { la posibilidad de causar daño a otra persona por } \\
\text { efecto del contacto de ese móvil. En este caso no } \\
\text { se llega a producir un control o recepción del } \\
\text { balón por la otra persona, pudiendo darse tanto en } \\
\text { colaboración como en oposición motriz. }\end{array}$ & $\begin{array}{l}\text { en oposición: balonmano, de } \\
\text { lanzamiento a puerta sin buscar } \\
\text { máxima potencia por temor de } \\
\text { lastimar al portero/a. } \\
\text { en colaboración: el rematador limita } \\
\text { su potencia para evitar dolor al } \\
\text { receptor. }\end{array}$ \\
\hline
\end{tabular}

El proceso de análisis se completó con el estudio de las relaciones existentes entre cada una de las subcategorías principales en relación con las tareas motrices de los distintos deportes trabajados.

Durante todo el proceso de codificación, el criterio de segmentación se centró en el mantenimiento del significado de la unidad gramatical (frase o párrafo) (Anguera et al. 2018; Vázquez Navarrete y Ferreira de Silva, 2006). Esto se justifica ya que en nuestro diseño de investigación la importancia de la extensión de cada unidad textual (aspecto cuantitativo) fue considerado menor frente a la posibilidad de disponer de su significación completa para interpretarla 


\section{Gestión emocional en futuros docentes de educación física}

correctamente desde el punto de vista cualitativo. Además, la vinculación de cada extracto del diario con la entrevista hacía necesario, en algunas ocasiones, que los extractos recogidos en esta última fueran amplios para poder comprender todo su sentido (Figura 4). En el caso concreto de que un extracto se refiriera a más de una subcategoría, se codificaba en todas ellas.

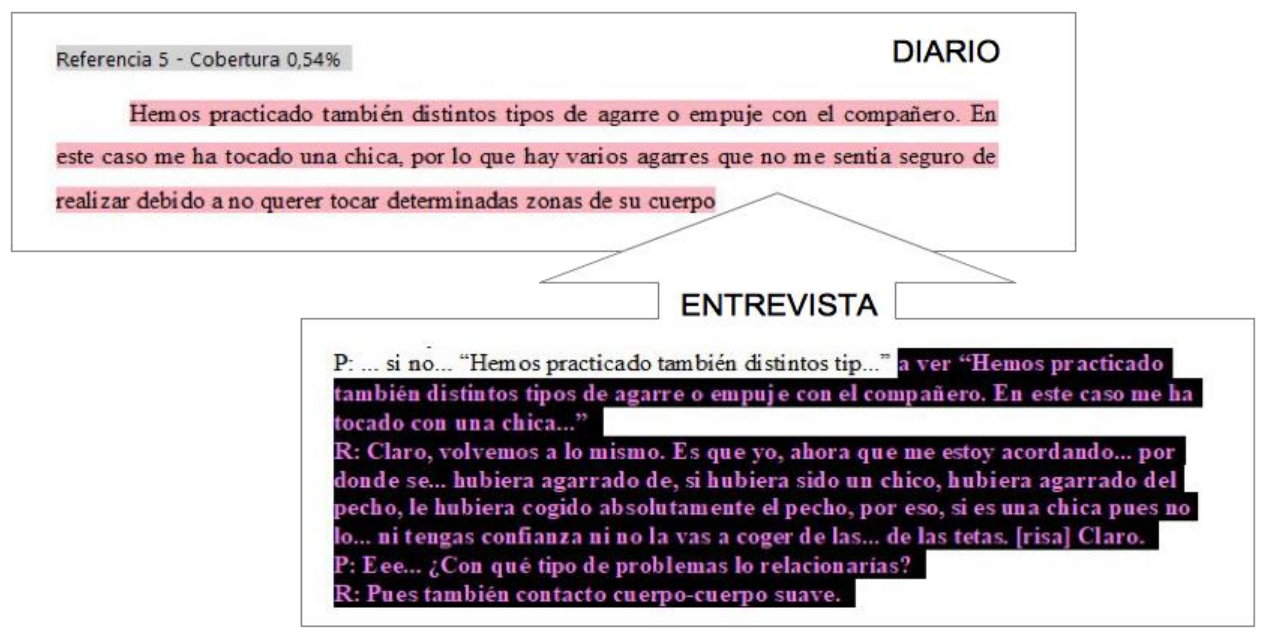

Figura 4. Ejemplo de segmentación de texto y relación entre entrevista y diario.

Posteriormente, se realizó la cuantificación de la frecuencia de términos relativos a las emociones recogidas en los diarios mediante la herramienta de consulta de frecuencia de palabras del programa Nvivo. La justificación de realizar únicamente el análisis léxico en los diarios se basa en evitar la duplicidad de términos que resultaría al incluir las entrevistas, puesto que estas fueron construidas en base a esos diarios. Además, en la transcripción de la entrevista aparecen también las intervenciones del investigador, necesarias para la comprensión de la misma, por lo que, de realizar el citado análisis, los datos resultarían falseados. Para el estudio de frecuencias, primero se descartaron las que no tenían relevancia para nuestro estudio. Las restantes se agruparon por raíces léxicas hasta concretar los 40 términos más relevantes. Por último, estas familias léxicas se agruparon en función de la clasificación Lazarus (2000). En este agrupamiento se tuvo en cuenta, también, aunque parcialmente, las Clasificación psicopedagógica de emociones de Bisquerra (2009). Ahora bien, en este caso, hemos preferido modificar los términos de emociones positivas o negativas por los de agradables o desagradables, para evitar confusiones sobre el sentido de las mismas, como el propio autor aconseja.

Dado que el estudio realizado se enmarca en el paradigma cualitativo, aún con apoyo de datos cuantitativos, para el control de la calidad del dato optamos por medidas de credibilidad en relación con la aplicación del método de indagación de forma rigurosa (Del Villar Álvarez, 1994; Moral Santaella, 2006). En concreto, las medidas tomadas en lo relativo a los instrumentos de investigación fueron:

a) La presentación de los diarios fue semi-abierta, dejando libertad a los sujetos para redactarlo de la manera que desearan; si bien se establecieron ciertas consideraciones: a) las sesiones recogidas debían abarcar todas las del curso; b) se fijó un formato que facilitase el análisis y; c) se focalizó la atención en las emociones emanadas de las tareas motrices realizadas, evitando condicionar los registros hacia una emoción determinada. Debido al trabajo extra que suponía la elaboración del diario, se decidió incluirlo dentro del sistema de calificación de la materia para incentivar la participación y reconocer el esfuerzo que suponía (Plummer, 1989), pero no como elemento obligatorio, buscando con ello la máxima veracidad del dato (Del Villar Álvarez, 1994).

b) Los participantes desconocían el objeto de estudio de la investigación, para conseguir máxima sinceridad en las respuestas y reducir, en la medida de lo posible, el efecto de la deseabilidad social. 


\section{Salgado-López, J.I., Sánchez-Molina, J.A.}

c) Para favorecer la exactitud en los registros se establecieron 10 minutos al final de la sesión para anotar las emociones vivenciadas (Sicilia Camacho, 1999). En este período, y para facilitar el recuerdo, el profesor enumeraba en la pizarra los nombres de las tareas motrices desarrolladas, agilizando así el proceso de asociación entre emociones y tareas.

d) Se estableció un control del proceso de elaboración de los diarios, programando dos recogidas de estos, después de la primera y cuarta sesión, devolviéndose con un informe individualizado que contenía indicaciones para reconducir, de ser necesario, su formato o contenido. Esta decisión fue necesaria, porque conocíamos, por experiencias previas, que a los estudiantes les resultaba difícil, inicialmente, centrar la redacción en las emociones suscitadas por las tareas motrices. Esto daba lugar a diarios construidos como fichero de tareas o en los que los estudiantes opinaban de manera crítica sobre la idoneidad de la tarea, lo que no era el objeto de los mismos. Tras la primera recogida se estableció una sesión para aclarar las dudas surgidas.

e) En el caso de la entrevista, se diseñó un protocolo en el que se incluyó un periodo inicial para establecer una vinculación personal con el sujeto, de cara a aumentar su implicación afectiva en el proceso y asegurar la veracidad y exactitud de sus aportaciones (Heinemann y Puig, 1997). La participación en la entrevista fue voluntaria, para favorecer también la veracidad de los datos aportados. Debido a ello, algunos estudiantes no participaron y sus diarios debieron ser desechados.

Durante el proceso de análisis de datos se adoptaron las siguientes medidas:

a) Exhaustividad y mutua exclusividad: La validez de contenido del sistema de categorías principal fue revisada por expertos pertenecientes a distintas universidades españolas. Además, la dimensión personal fue respaldada en tres foros internacionales (Autor, 2004a, 2004b y 2005). En estos trabajos la dimensión personal del sistema de categorías utilizado fue sometido a pruebas de fiabilidad interobservador obteniéndose un acuerdo entre observadores (Anguera, 1997) del 64\%, coeficiente de correlación $r=0.86$ con $p<0.01$ y coeficiente de determinación de $R^{2}=0.74$. b) A nivel general, se estableció un procedimiento de tres revisiones de la codificación (a la entrega de los diarios, antes de la entrevista y después de la introducción de los datos en el Nvivo), con un intervalo temporal entre ellas suficiente para provocar olvido (Anguera, 1997). Los resultados de estas codificaciones se compararon utilizando el índice Kappa de Cohen (Cohen, 1960) obteniendo un valor de $k=1$, por lo que se considera que la fiabilidad intraobservador es excelente. Además, la exactitud de la codificación está abalada por la entrevista. Con este último instrumento se pudo aplicar la concordancia consensuada (Anguera y Hernández Mendo, 2013) con los autores de los diarios, que se convierten así en colaboradores necesarios en la codificación. De este modo, los extractos textuales dudosos o conflictivos se codificaron en función de sus indicaciones. Cabe señalar, que estos procedimientos de control de dato a nivel general no se pudieron aplicar en el caso concreto de la dimensión social de la categoría de contactos suaves. Esto se debió a que, ante su ausencia en la literatura, la introducción de esta categoría fue posterior a la realización de la entrevista, después de contrastar la necesidad de su inclusión con otros investigadores expertos en el tema. En todo caso, se mantuvo una doble codificación con comparación mediante Kappa de Cohen, obteniéndose, de nuevo, un resultado máximo.

c) Para afianzar la credibilidad, los participantes tuvieron formación sobre la influencia de lo PADC en la enseñanza de los deportes de equipo, así como de su categorización. Esta se desarrolló en una sesión teórica de una hora, temporalizada después de la entrega de los diarios para su codificación y antes de la entrevista. Los contenidos de la misma se centraban básicamente en las aportaciones de Salgado-López et al. (2003). Además, en el periodo introductorio de la entrevista se repasaban los aspectos fundamentales de esa sesión, en especial la categorización. Con esto nos asegurábamos que conocieran los aspectos sobre los que iban a ser entrevistados previamente, sin influir con ello en la redacción de los mismos.

\section{RESULTADOS}

El primer resultado a destacar se observó al realizar la nube de palabras principales en relación con el objeto de estudio, tras limpiar los términos que no tenían interés para nuestro trabajo (Figura 5). Sin ser el aspecto cuantitativo un elemento principal en nuestro 


\section{Gestión emocional en futuros docentes de educación física}

diseño, la frecuencia de palabras sí resultó interesante desde el punto de vista cualitativo. De este modo, el término con significado emocional más citado fue miedo, recogido 387 veces en los diarios, seguido de diversión con 274 veces; es decir, existe una diferencia de más de 100 menciones entre ambos

Los resultados anteriores muestran ya de por sí la importancia que los participantes otorgaron a la vivencia del miedo, mayor aún al realizar el agrupamiento por emociones (Tabla 2). Ahora bien, en este caso, el agrupamiento de palabras entorno a la emoción alegría fue muy superior. De cualquier forma, aunque estas representaciones resultan muy claras, debemos ser cautos en su interpretación, puesto que ciertos términos podrían estar claramente falseados. Es el caso, por ejemplo, de los términos relacionados con la vergüenza, referidos normalmente de forma indirecta mediante expresiones del tipo me da palo, me da cosa, me da reparo, ... y que, por tanto, no son cuantificadas automáticamente por el programa. Además, hay que tener en cuenta que este tipo de representación tampoco recoge las negaciones de los términos (no se divertían, no disfruté, no me enfadé, no tuve miedo...). Es preciso pues acceder al conjunto de textos codificados para extraer una idea completa de la realidad.

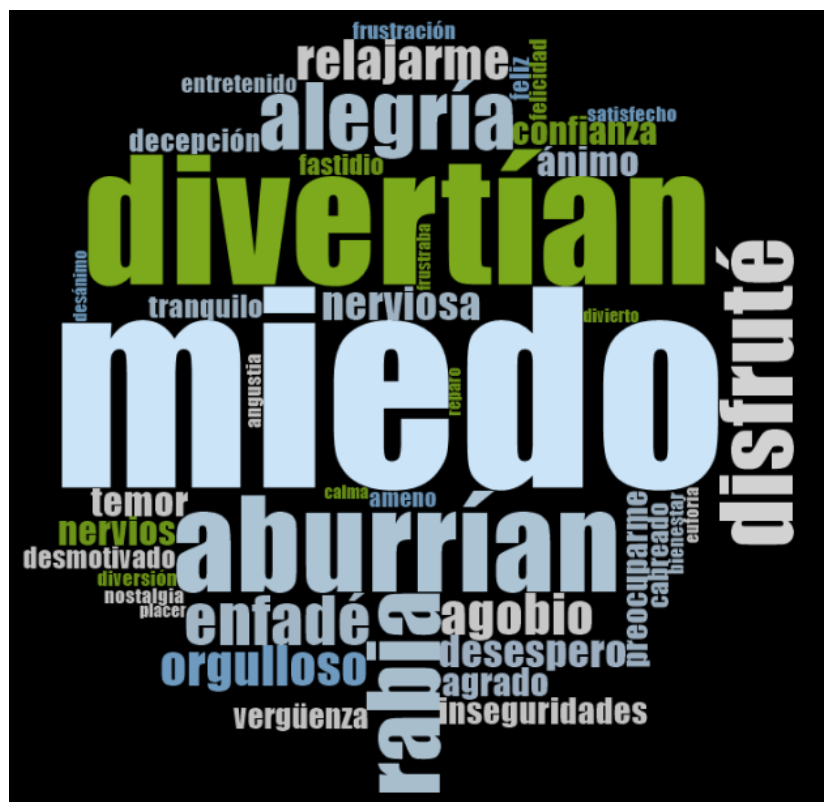

Figura 5. Nube de palabras con mayor frecuencia de aparición.

Tabla 2. Frecuencia de aparición términos relativos a emociones en los diarios

\begin{tabular}{llc}
\hline Emoción & Familia léxica & Frecuencia \\
\hline Emociones agradables & 681 \\
Alegría & agrado, alegría, ameno, ánimo, disfrute, diversión, entretenido, euforia & 42 \\
Amor & confianza & 208 \\
Felicidad & bienestar, calma, felicidad, placer, relajamiento, satisfecha, tranquilidad & 67 \\
Orgullo* & orgulloso & $\mathbf{9 9 8}$ \\
& total & 278 \\
\hline Emociones desagradables & 275 \\
Ansiedad & agobio, angustia, desespero, nervios, preocupación & 476 \\
Ira & cabreada, enfado, rabia, fastidio & 305 \\
Miedo & miedo, temor, inseguridad & 47 \\
Tristeza & aburrimiento, decepción, desánimo, desmotivación, frustración, nostalgia \\
Vergüenza & reparo, vergüenza & $\mathbf{1 3 8 1}$ \\
& total & \\
\hline *NOTA: La emoción orgullo no aparece en la clasificación de Bisquerra (2009) pero si en la de Lazarus (2000).
\end{tabular}




\section{Salgado-López, J.I., Sánchez-Molina, J.A.}

A modo de síntesis, la Tabla 3 muestra los resultados de la codificación principal. En ella se recoge: el número de sujetos que referenciaban cada subcategoría (columna $n^{\circ}$ ), su porcentaje frente al total de participantes (columna \%) y, en la última columna, las frecuencias totales de aparición de cada PADC.

Tabla 3. Frecuencia de aparición de los PADC.

\begin{tabular}{|c|c|c|c|c|c|}
\hline \multirow{2}{*}{ Dimensión } & \multirow{2}{*}{ Categoría } & \multirow{2}{*}{ Subcategoría } & \multicolumn{2}{|c|}{ Casos } & \multirow{2}{*}{ Frecuencia } \\
\hline & & & $\mathbf{n}^{\mathbf{o}}$ & $\%$ & \\
\hline \multirow{6}{*}{$\begin{array}{l}\text { Dimensión } \\
\text { personal }\end{array}$} & \multirow{2}{*}{$\begin{array}{l}\text { Contactos } \\
\text { interpersonales }\end{array}$} & bruscos & 16 & 100 & 114 \\
\hline & & suaves & 11 & 68,75 & 33 \\
\hline & \multirow[t]{2}{*}{$\begin{array}{l}\text { Contactos cuerpo- } \\
\text { suelo }\end{array}$} & $\begin{array}{l}\text { caídas } \\
\text { voluntarias }\end{array}$ & 15 & 93,75 & 95 \\
\hline & & $\begin{array}{l}\text { caídas } \\
\text { involuntarias }\end{array}$ & 14 & 87,5 & 38 \\
\hline & \multirow{2}{*}{$\begin{array}{l}\text { Contactos cuerpo- } \\
\text { objeto }\end{array}$} & recepciones & 2 & 12,5 & 4 \\
\hline & & golpeos & 14 & 87,5 & 82 \\
\hline \multirow{4}{*}{$\begin{array}{l}\text { Dimensión } \\
\text { social }\end{array}$} & \multirow{2}{*}{$\begin{array}{l}\text { Contactos } \\
\text { interpersonales }\end{array}$} & bruscos & 16 & 100 & 34 \\
\hline & & suaves & 4 & 25 & 6 \\
\hline & \multirow{2}{*}{$\begin{array}{l}\text { Contactos cuerpo- } \\
\text { objeto }\end{array}$} & golpeos & 2 & 12,5 & 7 \\
\hline & & pases & 0 & 0 & 0 \\
\hline
\end{tabular}

Como se aprecia en la Tabla 3, se codificaron registros en todas las subcategorías establecidas, excepto en una de la dimensión social: la de cuerpo-objeto pases. Los contactos bruscos figuraban entre los principales desencadenantes de PADC, tanto en su visión personal como en la social. Un ejemplo de ellos es el siguiente registro de Antia que afirmaba: "Cuando yo placaba, tenía miedo de hacerle daño a mi compañera y a mí misma, puesto que nunca lo había hecho y eso me retraía no dando todo de mí".

Otro grupo numeroso de registros codificados fueron los centrados en los problemas afectivos asociados a las caídas, tanto voluntarias como involuntarias. En su mayor parte estas se asociaban con las acciones de placaje en rugby, los lanzamientos en caída en balonmano o las planchas en voleibol. Una muestra clara de conducta motriz desajustada en función de un problema afectivo relacionado con las caídas involuntarias se muestra en el siguiente extracto del diario de Anabel: “... cuando me placaban a mí nunca salía con mucha velocidad porque me daba miedo que me tiraran con mucha fuerza."

Los problemas afectivos relacionados con los golpeos del balón en su dimensión personal estuvieron asociados fundamentalmente al puesto específico del portero en balonmano. Sería el caso de Agustyn, que señalaba: "También tuve sensaciones de miedo al encontrarme bajo palos y ver a un rival acercarse solo hacia mí lo que provocó que me apartara". Ahora bien, en algunos casos es precisamente en este rol donde más cómodos se encontraron los estudiantes, mostrando la influencia de la motivación en la superación de los PADC. Es el caso de Maria que, a pesar de obtener valores máximos en todas las subcategorías relacionadas con contactos con riesgo lesivo, al desarrollar el rol de portero señalaba: “... me ha hecho crecerme un poco y sentirme más segura de mi misma ya que no tenía ningún miedo a que el balón me impactara e intentaba parar los goles". Además, en esta subcategoría encontramos también otras referencias, como las centradas en el aprendizaje de gestos técnicos de voleibol, muchas veces relacionadas con la dureza de los balones; como, por ejemplo, "cada vez que golpeo de antebrazos, me «pica»y hace que golpee con miedo y con poca fuerza" (Fran).

Los resultados obtenidos en la subcategoría de problemas afectivos relacionados con los contactos suaves, tienen una menor incidencia que las subcategorías anteriores, tanto en la dimensión personal como social. Sin embargo, estos ponen de relevancia los aspectos de género en su aparición: "cuando tenía que defender no me sentía muy cómodo 


\section{Gestión emocional en futuros docentes de educación física}

por tener que tocar a los jugadores del equipo rival sobre todo si eran chicas puesto que no sabía cómo se iban a tomar que en algún lance del juego se me pudiera escapar la mano y tocarles más de la cuenta". En este caso, en los textos asociados a esta subcategoría es común la utilización de términos confusos que dificultaban su codificación. Un ejemplo aparece en este extracto referido a una tarea motriz de rugby relacionado tanto con la dimensión personal como social de esta subcategoría:

“... antes de que el adversario pudiera pasar el balón a uno de sus compañeros le teníamos que tocar por debajo de la cintura. Pero yo no podía no sé, sentía respeto (Me daba palo, vergüenza) por aquella persona a quien iba a tocar, ya que no nos conocíamos muy bien” (Marianna).

En cuanto a la dimensión social de los contactos cuerpo-objeto golpeos, pocas son las referencias recogidas. Una de ellas es la siguiente de Julio: "...varias veces tenía opciones de hacer remates fuertes y no los he hecho porque sabía que podían recepcionar mal y hacerse daño".

Para terminar con los resultados de la codificación principal, señalar que la subcategoría en la que menos registros se recogieron es la de recepciones; es más, estos resultados pueden estar influidos por el hecho de que las tareas que más dificultades presentaban, las relacionadas con el juego al pie en rugby, se había limitado su enseñanza a una única sesión:

“...he tenido un cierto temor al recoger el balón de rugby en el aire tras la patada de alguno de mis compañeros. Puesto que me acojonaba la velocidad a la cual iba, y no me sentía segura de cogerlo en el aire, así que la mayoría de las veces dejaba que este botara antes en el suelo" (Maria).

En lo referente a la descripción de los resultados por deportes, los contactos de mayor influencia en la aparición de PADC en rugby fueron los asociados a contactos interpersonales bruscos, tanto desde el punto de vista personal como social; $y$, los contactos con el suelo, fundamentalmente relacionados con las caídas involuntarias. Además, aunque en menor medida que los anteriores, se debe resaltar la presencia de problemas afectivos ligados a los contactos suaves. Por su parte, en balonmano se destacan los siguientes
PADC: los problemas derivados de los contactos con el suelo, mayoritariamente acciones de caídas voluntarias, y los golpeos del balón, relacionadas principalmente con el rol sociomotor de portero, por lo que estos últimos tendrían un componente involuntario. Por último, en voleibol sucede lo mismo que en balonmano en cuanto a los tipos de contacto implicados, si bien, en este caso, los golpeos se producen por una acción voluntaria del ejecutante.

$\mathrm{Si}$ nos centramos en las tareas motrices más conflictivas, las que mayor relación tuvieron con la aparición de PADC en rugby fueron las relacionadas con el aprendizaje del placaje, seguidas de las tareas de juego reducido-Tocata; también parecen ser conflictivas las tareas relacionadas con el aprendizaje de la melé. En balonmano destacaron las tareas vinculadas al aprendizaje del lanzamiento desde el extremo en caída y las de juego reducido. En voleibol las tareas más conflictivas fueron las relacionadas con el aprendizaje de las planchas. Por último, en los Juegos Predeportivos, categoría que agrupaba tareas jugadas válidas para la iniciación a todos los deportes anteriores, no se obtuvieron valores destacables en cuanto a incidencia de PADC.

Por su parte, en el estudio de los factores determinantes de la aparición de PADC los participantes señalaron un total de 29 factores, recogidos en la primera fila de la Tabla 4. Además, esta misma tabla, muestra los resultados obtenidos al cruzar los datos aportados por los sujetos relacionando la categorización principal, creada en base a los tipos de contactos, y la secundaria, centrada en los factores que podrían influir en la aparición de PADC. 
Salgado-López, J.I., Sánchez-Molina, J.A.

Tabla 4. Número de casos que citan cada uno de los factores en función de los tipos de problemas afectivos generados.

\section{Factores}

Subcategorías

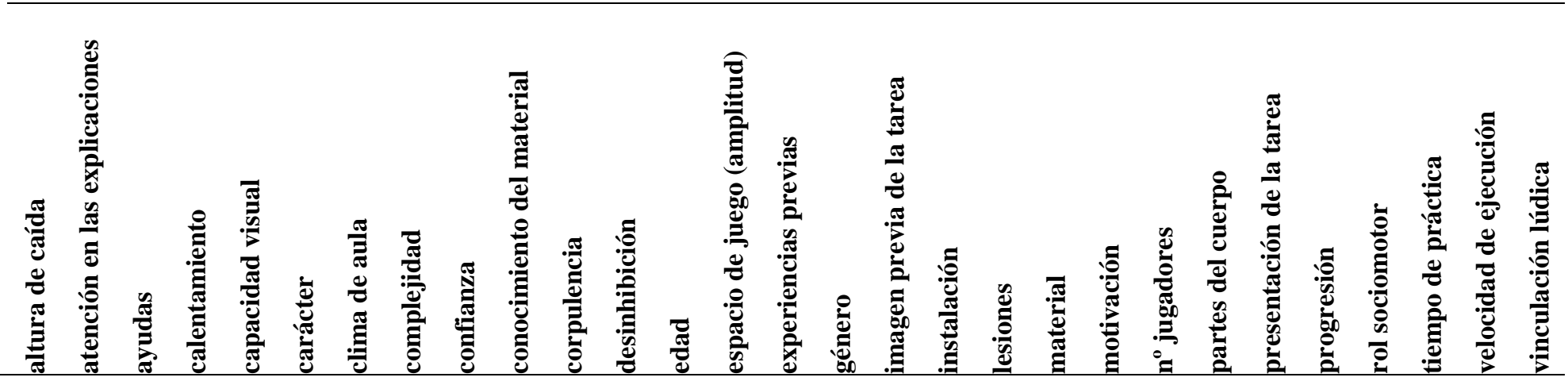

Dimensión personal

interpersonales bruscos interpersonales suaves

cuerpo-suelo. c. voluntarias

cuerpo-suelo. c. involuntarias

cuerpo-objeto recepciones

cuerpo-objeto golpeos

\section{Dimensión social}

interpersonales bruscos

interpersonales suaves

$\begin{array}{llllllll}5 & 0 & 0 & 1 & 0 & 0 & 0 & 2\end{array}$

\begin{tabular}{|c|c|c|c|c|c|c|c|c|c|c|c|c|c|c|c|c|c|c|c|c|c|c|c|c|c|c|c|c|}
\hline 0 & 0 & 0 & 0 & 0 & 0 & 1 & 0 & 6 & 0 & 1 & 0 & 0 & 0 & 1 & 3 & 2 & 0 & 0 & 0 & 0 & 0 & 6 & 0 & 0 & 2 & 0 & 0 & 0 \\
\hline 6 & 1 & 0 & 1 & 0 & 0 & 1 & 2 & 0 & 0 & 1 & 0 & 0 & 0 & 11 & 0 & 5 & 2 & 1 & 11 & 4 & 0 & 1 & 1 & 3 & 3 & 1 & 5 & 0 \\
\hline 4 & 0 & 0 & 0 & 0 & 0 & 1 & 0 & 0 & 0 & 1 & 0 & 0 & 0 & 3 & 0 & 2 & 3 & 0 & 8 & 1 & 0 & 1 & 0 & 3 & 4 & 0 & 6 & 0 \\
\hline 0 & 0 & 0 & 2 & 1 & 0 & 0 & 0 & 0 & 0 & 0 & 0 & 0 & 0 & 0 & 0 & 0 & 1 & 0 & 0 & 0 & 0 & 0 & 0 & 0 & 0 & 0 & 1 & 0 \\
\hline 0 & 0 & 0 & 0 & 0 & 0 & 0 & 0 & 0 & 0 & 1 & 0 & 0 & 4 & 7 & 1 & 3 & 2 & 2 & 5 & 5 & 0 & 9 & 0 & 0 & 13 & 2 & 11 & 2 \\
\hline
\end{tabular}

\begin{tabular}{lllllllllllllllllllllllllllllllll}
3 & 0 & 0 & 1 & 0 & 0 & 0 & 0 & 1 & 0 & 2 & 0 & 0 & 0 & $\mathbf{4}$ & $\mathbf{8}$ & 1 & 0 & 1 & 2 & 1 & 0 & 2 & 0 & 1 & $\mathbf{5}$ & 0 & 2 & 0 \\
0 & 0 & 0 & 0 & 0 & 0 & 1 & 0 & $\mathbf{3}$ & 0 & 0 & 0 & 0 & 0 & 0 & $\mathbf{2}$ & 0 & 0 & 0 & 0 & 0 & 0 & $\mathbf{2}$ & 0 & 0 & 1 & 0 & 0 & 0 \\
0 & 0 & 0 & 0 & 0 & 0 & 0 & 0 & 0 & 0 & 0 & 0 & 0 & 0 & 0 & 0 & 0 & 0 & 0 & 0 & 0 & 0 & 1 & 0 & 0 & 1 & 0 & $\mathbf{2}$ & 0 \\
0 & 0 & 0 & 0 & 0 & 0 & 0 & 0 & 0 & 0 & 0 & 0 & 0 & 0 & 0 & 0 & 0 & 0 & 0 & 0 & 0 & 0 & 0 & 0 & 0 & 0 & 0 & 0 & 0 \\
\hline
\end{tabular}

cuerpo-objeto pases

Nota. En la tabla se han resaltado los tres valores más altos de cada una de las subcategorías. La abreviatura "c." hace referencia a "caídas". 


\section{Gestión emocional en futuros docentes de educación física}

\section{DISCUSIÓN}

\section{Vivencia emocional asociada a las tareas del contacto}

Tradicionalmente, tanto en la bibliografía (SalgadoLópez, 2020), como en las expresiones de los participantes en investigaciones similares (SalgadoLópez, 2007), el concepto de PADC aparece asociado con la emoción miedo. En este sentido, son comunes las expresiones como miedo al contacto, miedo a la caída, miedo al balón, etc. Los resultados parecen confirmar esta asociación. Ahora bien, esto dejaría de lado las emociones relacionadas con los aspectos no vinculados con la integridad física de la persona sino con su esfera psicológica. Tal es el caso de las emociones ligadas a términos como vergüenza, agobio, reparo o angustia, todos ellos presentes en los documentos analizados.

Centrándonos en el estudio general de las emociones recogidas en este estudio, el análisis frecuencial de los términos relacionados con las emociones aparecidos en los diarios (Tabla 2), parece confirmar el destacado lugar que ocupan las emociones desagradables en las situaciones de aprendizaje de tareas motrices relacionadas con deportes de cooperación-oposición. Así, la comparación entre las frecuencias totales de ambas familias de emociones señala una mayor y más importante presencia de términos asociados a emociones desagradables que a agradables. La diferencia es, además, en cantidad suficiente como para ser tenidas en cuenta: más de un tercio superior. Esto contradice la mayor parte de los estudios recogidos por Martínez-Martínez y Valero-Valenzuela (2019) que señalan que, sea cual sea el tipo de práctica motriz, la vivencia de emociones positivas supera ampliamente a las negativas y ambiguas. En cualquier caso, algunos de esos estudios señalan que el dominio en el que se generan un mayor número de emociones desagradables es, precisamente, en el que nos centramos: el de colaboración-oposición (Alonso, Gea y Yuste, 2013; Lavega Burgués, Aráujo y Jaqueira, 2013; Lavega, Filella, et al., 2013). La justificación de esta diferencia habría que buscarla, tal vez, en la metodología utilizada. En concreto, los estudios citados utilizan la escala GES (Games and Emotions Scale) (Lavega, March y Filella, 2013) a lo largo de un número de sesiones determinadas, nunca un año académico completo. Además, la propia selección de las tareas motrices podría tener influencia en los resultados, en función de la existencia o no de contacto.

Otro resultado de interés en relación con la descripción emocional que los estudiantes realizan es la aparición de la emoción orgullo, no recogida en el citado GES, instrumento ampliamente utilizado en las investigaciones más recientes sobre emociones y prácticas motrices. A la vista de los resultados, creemos que su presencia, mayor incluso que la de la vergüenza, podría ser reconsiderada.

Influencia de las emociones asociadas al contacto en el aprendizaje

Los resultados cualitativos de las unidades textuales muestran que las emociones vivenciadas ante ciertas situaciones de contacto pueden tener una influencia negativa en el aprendizaje, cuestión que ya se había puesto de manifiesto anteriormente (Canales-Lacruz y Casedas-Gerez, 2018; Canales-Lacruz y Pina-Blanco, 2014; Salgado-López, 2014). Esta influencia puede ser de mayor o menor grado en función de una serie de factores que serán comentados a continuación.

\section{Los Problemas Afectivos Derivados del Contacto y factores que influyen en su aparición}

En nuestro estudio, la aparición de problemas afectivos, ligados a contactos bruscos, parece depender, fundamentalmente, de las experiencias motrices previas vividas por el sujeto que las pone en práctica y la imagen previa que se haya creado el individuo sobre la tarea motriz a desarrollar. Esto es similar a lo aportado por Lavega, Filella, Agulló, Soldevila y March (2011) que señalaban que las personas que habían practicado regularmente deportes de equipo con anterioridad a su estudio, registraban los valores máximos para las emociones agradables. De manera similar, Gea García, Alonso-Roque, Yuste Lucas y Garcés de los Fayos Ruiz (2016) informaban que los estudiantes sin "huella deportiva" mostraban mayores niveles de activación emocional. En este mismo sentido se encuentran los trabajos de MujicaJonhson y Jiménez (2019) que mostraban también la influencia de las experiencias deportivas previas en la percepción emocional ante una situación práxica nueva. Después de estos factores principales, también el rol que desempeñe el sujeto en la tarea, la velocidad de ejecución y el material utilizado parecen estar relacionados con estos problemas. Además, la 


\section{Salgado-López, J.I., Sánchez-Molina, J.A.}

corpulencia del otro participante en la tarea favorece el surgimiento de PADC tal como señalaban CanalesLacruz y Casedas-Gerez (2018). A estos factores les siguen las lesiones que pueda haber sufrido con anterioridad el sujeto, como ya había señalado Chase, Magyar y Drake (2005) dentro de la gimnasia deportiva. Del mismo modo las partes del cuerpo implicadas, la altura de caída y la progresión que se ha desarrollado para el aprendizaje de la propia tarea parecen influir claramente en la aparición de problemas afectivos en este tipo de contactos. Asimismo, podemos decir que podría haber cierta influencia en función del género de los actores implicados en la acción, aunque esto no es tan claro aquí como en los resultados de la subcategoría que presentamos en el párrafo siguiente.

Por su parte, los contactos suaves parecen seguir un patrón similar tanto en su dimensión personal como social. En esta subcategoría, los principales factores que pueden ser generadores de conflictos afectivos son la confianza que tengan mutuamente los participantes en la tarea motriz y la parte del cuerpo con la que se contacta. Este último ya había sido destacado por Turrán Eguren (2011) en situaciones práxicas expresivas. Relacionado con esto, también el género de los implicados parece jugar, una baza importante casi en contraposición con la visión tradicionalmente masculina del deporte (Alvariñas Villaverde, Fernández Villarino y López Villar, 2009). Estos resultados relacionados con los contactos suaves establecen también cierto paralelismo con los encontrados por Coqueiro Pires de Sousa y Caramaschi (2011) en la enseñanza de bailes de salón o por Canales-Lacruz y Rey-Cao (2014) en la enseñanza de tareas expresivas a futuros docentes de EF. En menor medida, el rol sociomotor desarrollado también se señala como otro factor que parece influir en la aparición de las emociones relacionadas con este tipo de PADC.

Las caídas han sido también generadoras de PADC, tal como ya señalaran Canales Lacruz y CasedasGerez (2018) y Torres Tobío (1998) en balonmano y Gutiérrez Santiago y Cancela Carral (2004) en voleibol, si bien no utilizan el término de PADC. Las dos subcategorías asociadas con las caídas parecen mostrar una pauta similar en cuanto a los factores más involucrados, como son: la altura de caída, el material en el que se cae, la velocidad de la ejecución y, con menor incidencia, la progresión de aprendizaje y la instalación utilizada. La mayor diferencia entre ambas subcategorías está en el factor volitivo de las caídas voluntarias lo que hace que la influencia de factores asociados a la motivación, experiencias previas y la imagen que se tenga de la actividad sea mucho más marcada. Además, el hecho de que la actividad sea controlada por el ejecutante hace también que el material sobre el que se cae influya mucho más que en las caídas involuntarias.

No se han encontrado grandes resultados asociados a la subcategoría de recepciones, tal vez relacionado con la influencia de la edad madurativa (Palao y Guzmán, 2007) y las experiencias previas. Ahora bien, se observan indicios de cierta relación entre la aparición de problemas afectivos asociados a las recepciones y el calentamiento realizado. Así, un mal calentamiento favorecería la aparición de reticencias a la hora de realizar las primeras acciones de aprehensión del móvil. Se citan también otras que podrían ser de mayor calado en función de las características de la población con la que se realicen las tareas, como es el caso de la velocidad del móvil y los problemas de visión del ejecutante.

En las tareas que implican golpeos con el balón, los resultados parecen indicar que dependen de los roles desarrollados por los participantes, en clara relación con el rol de portero en balonmano, aspecto también resaltado por Canales-Lacruz y Casedas-Gerez (2018) en edades de etapa alevín. A este factor hay que sumar la velocidad de ejecución de la acción y las partes del cuerpo implicadas en el golpeo. Esto también es paralelo a lo recogido por Canales-Lacruz y PinaBlanco (2014) que señalaban el golpeo de antebrazos como la mayor fuente de PADC en el aprendizaje del voleibol. Además, las experiencias previas de los sujetos, su motivación y el material con el que esté elaborado el móvil parecen tener también cierta influencia.

Centrándonos en la dimensión social de los PADC por contactos bruscos se puede destacar, tal vez, cierta relación con los factores asociados a las experiencias previas, los roles desarrollados por cada uno de ellos $\mathrm{y}$, sobre todo, con el género de los sujetos implicados.

De manera similar la dimensión social de los PADC por contactos cuerpo-objeto golpeos parece que surge bajo la influencia del rol desarrollado en la situación 


\section{Gestión emocional en futuros docentes de educación física}

motriz y de su velocidad de ejecución. En todo caso, los resultados para esta subcategoría y, en parte, para la anterior podrían ser esperados al cumplir los estereotipos de género actuales (Canales-Lacruz y Rey-Cao, 2014) ya que la mayoría responden a individuos masculinos de gran corpulencia.

\section{CONCLUSIONES}

Para finalizar, debemos hacer constar que el marco cualitativo, junto con el diseño del estudio y su muestra, convierten este trabajo en una aproximación a la complejidad del objeto de estudio. Esto impide la posibilidad de generalización, aunque abre las puertas a una investigación más profunda en las relaciones entre contacto y emociones dentro de las prácticas motrices. Es por ello, que no creemos que en un estudio de las características del que presentamos se pueda hablar de conclusiones cerradas. Ahora bien, sí creemos necesario realizar una síntesis de las principales aportaciones del trabajo. Somos conscientes, sin embargo, que esto nos obliga a dejar de lado muchas de las aportaciones cualitativas que salpican los resultados y que describen, tal vez mejor, la realidad. Así, las principales aportaciones que cabría extraer son:

a) Los PADC son generados por emociones desagradables, entre las que destaca el miedo, pero sin dejar de lado otras como la ansiedad o incluso la vergüenza. Además, la comparación de frecuencias entre términos asociados a emociones muestra un mayor número de ellas de carácter desagradable frente a las de tipo agradable, en oposición a lo establecido en la bibliografía. Ahora bien, el tipo de estudio desarrollado no permite generalizaciones, por lo que es aconsejable continuar indagando en estos aspectos.

b) Se han encontrado evidencias en las que los PADC dificultan el aprendizaje, al limitar la participación de algunos sujetos en las tareas motrices propuestas, generando conductas motrices desajustadas o, incluso, llegando a inhibir su participación en la tarea. Ahora bien, existen también algunas muestras de que la superación de las reticencias iniciales son un acicate para la práctica, generando incluso emociones agradables.

c) Los sujetos estudiados han aportado referencias sobre la existencia de problemas afectivos relacionados con contactos interpersonales, cuerpo- suelo y cuerpo-objeto. Cabe destacar la aparición de PADC más allá de una visión únicamente basada en el mantenimiento de la integridad física del propio individuo y de su vinculación con el miedo. Muestra de ello es que se registraron tanto en relación a contactos suaves, asociados con emociones próximas a la vergüenza, como derivados de los temores a dañar a otros participantes en la actividad. Con todo, podemos que decir que los PADC que puedan poner en riesgo la integridad física del propio individuo parecen ser mayoritarios porcentualmente, aunque esto debería de ser corroborado con otros estudios de corte más cuantitativo.

d) Han surgido gran variedad de factores de influencia en la aparición de los PADC, superando incluso los adelantados por Salgado-López et al. (2003). Estos resultados pueden servir de punto de partida para una sistematización de la práctica docente en los deportes vistos en función de los factores registrados. En concreto, los factores más señalados en relación a la aparición de PADC fueron, por orden: la altura de caída, la confianza en los otros participantes en la tarea motriz, la corpulencia propia o de los otros, las experiencias previas, el género, la imagen previa que crea el estudiante de la tarea motriz a realizar, el material utilizado durante la práctica, las partes del cuerpo implicadas en la tarea motriz, los roles sociomotores a cumplir y la velocidad de ejecución. Cabe señalar que su incidencia es distinta en función del tipo de contacto.

\section{APLICACIONES PRÁCTICAS Y LÍNEAS DE FUTURO}

Los resultados obtenidos señalan la necesidad de tener en cuenta la aparición de PADC en los procesos de enseñanza-aprendizaje centrados en los deportes sociomotores vistos en la educación superior. Esto debería hacer reflexionar a los docentes que desarrollen estos contenidos sobre la necesidad de adaptar las tareas, desarrollando progresiones en función de los factores que se han señalado como más influyentes en la aparición a cada uno de esos problemas. Seguiríamos con ello la línea de lo establecido en sus respectivas áreas a nivel empírico por, entre otros, Bonnefoy, et al. (2000), Collinet (2000), Drauchke, et al. (2002), Gutiérrez Santiago y Cancela Carral (2004), Rugby Football Union (1985), Salgado-López et al. (2003), Torres Tobío (1998) o Usero Martín (1993). Con ello, además de evitar la 


\section{Salgado-López, J.I., Sánchez-Molina, J.A.}

aparición de vivencias emocionales no placenteras que dificulten el bienestar subjetivo de los estudiantes (Diener, Lucas y Oishi, 2018), se favorecería el aprendizaje motor, al controlar los factores relacionados con el contacto que pudieran entorpecerlo.

Si bien la investigación se centra en un entorno muy concreto, cabe hipotetizar que los resultados podrían ser similares en otros entornos y edades, por ejemplo, en la EF escolar, como parecen señalar también los trabajos de Canales-Lacruz y Casedas-Gerez (2018) y Canales-Lacruz y Pina-Blanco (2014). Además, también se podría profundizar en la relación de los factores relacionados con la aparición de los PADC con la vivencia emocional de los estudiantes. Cabría también la posibilidad de estudiar la existencia de PADC en otras prácticas motrices como ya parecen adelantar los trabajos de Canales-Lacruz (2006), Coqueiro Pires de Sousa y Caramaschi (2011) y Turrán Eguren (2011).

\section{REFERENCIAS}

1. Aguilar Aguilar, R.D. (2012). Curso básico de balonmano. Recuperado de http://viref.udea.edu.co/contenido/menu_alter no/apuntes/ac-55_balonmano.pdf

2. Alonso, J. I., Gea, G., Yuste, J. L. (2013). Formación emocional y juego en futuros docentes de Educación física. Revista Electrónica Interuniversitaria de Formación del Profesorado, 16(1), 97-108. https://doi.org/10.6018/reifop.16.1.179461

3. Alvariñas Villaverde, M., Fernandez Villarino, Mª.A., López Villar, C. (2009). Actividad física y percepciones sobre deporte y género. Revista de Investigación en Educación (6), 113-122. www.webs.uvigo.es/reined/ojs/index.php/rei ned/article/viewFile/58/52

4. Anguera, Ma.T. (1997). Metodología observacional de las ciencias humanas. Madrid: Cátedra.

5. Anguera, $\mathbf{M}^{\mathrm{a}}$.T., Blanco Villaseñor, A., Hernández Mendo, A., Losada, J. L. (2011). Diseños observacionales: ajuste y aplicación en psicología del deporte. Cuadernos de Psicología del Deporte, 11(2), 63-76. https://revistas.um.es/cpd/article/view/13324 $1 / 122911$

6. Anguera, Ma.T., Hernández Mendo, A. (2013). La metodología observacional en el ámbito del deporte. E-balonmano.com: Revista de Ciencias del Deporte, 9(3), 135$161 . \quad$ http://www.ebalonmano.com/ojs/index.php/revista/article/ view/139/pdf_20

7. Anguera, Ma.T., Portell, M., ChacónMoscoso, S., Sanduvete-Chaves, S. (2018). Indirect Observation in Everyday Contexts: Concepts and Methodological Guidelines within a Mixed Methods Framework. Front. Psychol. 9(13). https://doi.org/10.3389/fpsyg.2018.00013

8. Ato, M., López, J.J., Benavente, A. (2013). Un sistema de clasificación de los diseños de investigación en psicología. Anales de Psicología, 29(3), 1038-1059. https://doi.org/10.6018/analesps.29.3.178511

9. Bardin, L. (1996). El análisis de contenido. Madrid: Akal Ediciones.

10. Bernard, M. (1985). El cuerpo. Barcelona: Paidós Ibérica.

11. Bisquerra, R. (2009). Psicopedagogía de las emociones. Madrid: Síntesis

12. Bonnefoy, G., Lahuppe, H., Né, R. (2000). Enseñar voleibol para jugar en Equipo. Barcelona: Inde.

13. Campo, M., Mellalieu, S., Ferrand, C., Martinent, G., Rosnet, E. (2012). Emotions in Team Contact Sports: A Systematic Review. Sport Psychologist, (26), 62-97. https://doi.org/10.1123/tsp.26.1.62

14. Canales-Lacruz, I. (2006). Consecuencias pedagógicas de la mirada y el tacto en la expresión corporal. Tesis doctoral, Universitat de Lleida, Lleida, España. www.tdx.cat/bitstream/handle/10803/8205/Ti cl1de1.pdf;jsessionid=063ED0BA14C1AF51 544711B7FA750312? sequence $=1$

15. Canales-Lacruz, I., Casedas-Gerez, A. (2018). Miedo al contacto en balonmano percibido por los jugadores de un equipo de categoría alevín. $17(2)$. 


\section{Gestión emocional en futuros docentes de educación física}

https://revistakronos.info/articulo/miedo-alcontacto-en-balonmano-percibido-por-losjugadores-de-un-equipo-de-categoria-alevin2476-sa-c5c1124cbb84f8/

16. Canales-Lacruz, I., Pina-Blanco, I. (2014). El miedo al contacto en el voleibol. Percepciones del alumnado de educación física. Ágora para la educación física y el deporte, 16(2), 122136. revista.blogs.uva.es/files/2014/12/agora_16_ 2c_canales_et_pina.pdf

17. Canales-Lacruz, I., Rey-Cao, A. (2014). Diferencias de género percibidas por el alumnado en la interacción visual y táctil de las tareas de expresión corporal. Movimento, 20(1), 169-192. https://doi.org/10.22456/1982-8918.39271

18. Castañer, M., Camerino, O., Anguera, $M^{a}$.T. (2013). Métodos Mixtos en la investigación de las Ciencias de la Actividad Física y el Deporte. Apunts: Educación Física i Esports, (112), 11-16. https://doi.org/10.5672/apunts.20140983.es.(2013/2).112.01

19. Chase, M., Magyar, M., Drake, B. (2005). Fear of injury in gymnastics: Self-efficacy and psychological strategies to keep on tumbling. Journal of Sports Sciences, 2(5), 465- 475. https://doi.org/10.1080/02640410400021427

20. Cohen, J. (1960). A coefficient of agreement for nominal scales. Educational and Psychological Measurement, 20, 37-46. https://doi.org/10.1177/00131644600200010 4

21. Collinet, S. (2000). Les Fondamentaux du Rugby: Manuel pour l'éducateur et l'entraîneur. Niveau 1. Niveau 2. Paris: Anphora.

22. Coqueiro Pires de Sousa, N., Caramaschi, S (2011). Contato corporal entre adolescentes através da dança de salão na escola. Motriz: revista de educación fisica, 17(4), 618-629. https://doi.org/10.1590/s198065742011000400006

23. Corless, B. (1995). El Rugby. Barcelona: Hispano Europea.
24. Christina, R.W., Corcos, D.M. (1988). Coaches guide to teachig sports skills. Champaign, Illinois: Human Kinetics.

25. Davis, F. (1987). La comunicación no verbal. Madrid: Alianza Editorial.

26. Del Villar Álvarez, F. (1994). La credibilidad de la investigación cualitativa en la enseñanza de la Educación Física. Apunts: Educació Física $i$ Esports, (37), 26-33. https://hemeroteca.revistaapunts.com/es/hemeroteca/?article $=882$

27. Descamps, M-A. (1990). El Lenguaje del cuerpo y la comunicación corporal. Bilbao: Deusto.

28. Diener, E., Lucas, R., Oishi, S. (2018). Advances and open questions in the science of subjective well-being. Collabra: Psychology, 4(1), 1-49. https://doi.org/10.1525/collabra.115

29. Drauchke, K., Schulz, A., Utz, M. (2002). El Entrenador de Voleibol. Barcelona: Paidotribo.

30. Fast, J. (1994). El Sublenguaje del Cuerpo: Gestos, posturas y distancias en las relaciones personales en la empresa. Barcelona: Paidós.

31. Flick, U. (2015). El diseño de investigación cualitativa. Madrid: Morata.

32. Gea García, G.M., Alonso-Roque, J.I., Yuste Lucas, J.L., Garcés de los Fayos Ruiz (2016). Los juegos deportivos y su influencia en la gestión emocional en universitarios. Cuadernos de Psicología del Deporte, 16(3), 101-112.

http://scielo.isciii.es/pdf/cpd/v16n3/ciencias_ deporte3.pdf

33. Gutiérrez Santiago, A., Cancela Carral, J.M. (2004). Una propuesta de aprendizaje del juego acrobático en el voleibol. Lecturas: Educación Física y Deportes, (74), 47-58. https://www.efdeportes.com/efd74/voleib.ht $\mathrm{m}$

34. Hall, E.T. (1989). El lenguaje silencioso. Madrid: Alianza Editorial. 


\section{Salgado-López, J.I., Sánchez-Molina, J.A.}

35. Hall, E.T. (2003). La dimensión oculta. Madrid: Siglo XXI.

36. Heinemann, K. (2003). Introducción a la metodología de la investigación empírica en las Ciencias del Deporte. Barcelona: Paidotribo.

37. Heinemann, K., Puig, N. (1997). Emocions en l'esport. Esbós d'una anàlisi sociològica. Revista Catalana de Sociología (5). http://revistes.iec.cat/index.php/RCS/article/v iew/4161/pdf_1461

38. Hernández Mendo, A., Molina Macías, M. (2002). Cómo usar la observación en la psicología del deporte: principios metodológicos. Lecturas: Educación Física y Deportes, (49).

https://www.efdeportes.com/efd49/obs1.ht

39. Hernández Moreno, J. (1994). Análisis de las estructuras del juego deportivo. Barcelona: Inde.

40. Jaqueira, A., Lavega, P., Lagardera, F., Araújo, P., Rodrigues, M. (2014). Educando para la paz jugando: Género y emociones en la práctica de juegos cooperativos competitivos. Educatio Siglo XXI. 32(2), 1532. https://doi.org/10.6018/j/194071

41. Lavega, P., Araujo, P., Jaqueira, A.R. (2013). Enseñar competencias motrices y emocionales en estudiantes universitarios. Cutura_Ciencia_Deporte, $\quad 8(22), \quad$ 5-15. https://doi.org/10.12800/ccd.v8i22.219

42. Lavega, P., Costes, A., Prat, Q. (2015). Educar competencias emocionales en futuros profesores de Educación Física. Revista Interuniversitaria de Formación del Profesorado, 29(2), 61-73. http://www.redalyc.org/articulo.oa?id=27443 659005

43. Lavega, P., Filella, G., Agulló, M M $^{\mathrm{a} . J}$., Soldevila, A., March, J. (2011). Conocer las emociones a través de juegos: Ayuda para los futuros docentes en la toma de decisiones. Electronic Journal of Research in Educational Psychology, 9(24), 617-640. https://doi.org/10.25115/ejrep.v9i24.1459
44. Lavega, P., Filella, G., Lagardera, F., Mateu, M., Ochoa, J. (2013). Juegos motores y emociones. Cultura y Educación, 25(3), 347360. https://doi.org/10.1174/11356401380774973 1

45. Lavega, P., March, J., Filella, G. (2013). Juegos deportivos y emociones. Propiedades psicométricas de la escala GES para ser aplicada en la Educación Física y el Deporte. Revista de Investigación Educativa, 31(1), 151-165.

https://doi.org/10.6018/rie.31.1.147821

46. Lazarus, R.S. (2000). How Emotions Influence Performance in Competitive Sports, The Sport Psychologist, 14(3), 229-252. https://doi.org/10.1123/tsp.14.3.229

47. Martínez-Martínez, F.D., Valero-Valenzuela, A. (2019). Vivencia emocional del alumnado universitario en educación física: revisión sistemática. Revista Iberoamericana de psicología del ejercicio y el deporte, 14(2), 91-96. https://www.ripedonline.com/articles/emotional-experience-ofuniversity-students-in-physical-educationsystematic-review.pdf

48. Montagu, A., Matson, F. (1989). El contacto humano. México: Paidós Studio.

49. Moral Santaella, C. (2006). Criterios de validez en la investigación cualitativa actual. Revista de Investigación Educativa, 24(1), 147-164.

https://revistas.um.es/rie/article/view/97351

50. Mujica-Johnson, F.N., Orellana-Arduiz, N.C., Concha-López, R-F. (2017). Emociones en la clase de Educación Física: revisión narrativa (2010-2016). Ágora para la Educación Física $y$ el Deporte 19(1), 119-134. doi: 10.24197/aefd.1.2017.119-134

51. Mujica-Johnson, F.N., Jiménez, A.C. (2019). Percepción emocional en la asignatura de Baloncesto de estudiantes del Grado en Ciencias del Deporte: Estudio piloto. Cuadernos de Psicología del Deporte, 19(2), 160-174. https://doi.org/10.6018/cpd.347161 


\section{Gestión emocional en futuros docentes de educación física}

52. Palao, J.M., Guzmán, S. (2007). Efecto de la red, la interacción, y el tipo de balón sobre la participación y la percepción del alumno en la iniciación al pase de dedos en voleibol. Motricidad: Revista de Ciencias de la Actividad Física y del Deporte (18), 163-178. https://recyt.fecyt.es/index.php/ejhm/article/d ownload/56255/34174

53. Pease, A., Pease, B. (2006). El lenguaje del cuerpo. Barcelona: Amat.

54. Peitersen, B. (2007). Técnica del fútbol. El $A B C$ del entrenamiento juvenil. Barcelona: Paidotribo.

55. Plummer, K. (1989). Los documentos personales. Introducción a los problemas y a la bibliografía del método humanista. Madrid: Siglo XXI.

56. Rovira, G. (2010). La conciencia sensitiva en la formación docente. Estudio de casos: las vivencias de los estudiantes de magisterio suscitadas en la práctica de situaciones motrices introyectivas. Tesis doctoral, Universitat de Lleida, Lleida, España. http://www.tesisenred.net/handle/10803/8204

57. Rovira, G., López-Ros, V, Lagardera, F., Lavega, P., March, J. (2014). Un viaje de exploración interior: Emociones y estado de ánimo en la práctica motriz introyectiva. Educatio Siglo XXI. 32(2), 105-126. https://doi.org/10.6018/j/194111

58. Rugby Football Union (1985). Even Better Rugby. Middlesex: Autor

59. Salgado-López, J.I., Eslava Oriol, I., Montes Lasheras, J.M., Mariño Pego, C. (2003). Factores a tener en cuenta en la enseñanza de tareas motrices que impliquen contacto físico. Revista de Educación Física (91), 27-38.

60. Salgado-López, J.I., Rovira, G. (2004a). Análisis de los problemas Psico-afectivos derivados del contacto en deportes sociomotrices de colaboración-oposición. En: Actas al III Congreso de la Asociación Española de Ciencias del Deporte. Valencia, España.
61. Salgado-López, J.I., Rovira, G. (2004b). Problemas psico-afectivos derivados del contacto en sesiones de Educación Física con actividades sociomotrices de colaboraciónoposición. En: Actas al I Congreso Internacional de Educación Física- $2^{o}$ simposio de Psicomotricidad Infantil. Varadero, Cuba.

62. Salgado-López, J.I., Rovira, G. (2005). Los problemas Psico-afectivos derivados del contacto en Educación Física: Implicaciones en los deportes sociomotrices de colaboración-oposición. En: Congreso Sudamericano FIEP-2005 y $10^{a}$ Jornada de Educación Física del Mercosur. Cordoba, Argentina.

63. Salgado-López, J.I. (2007). Aversión al contacto: Análisis de los problemas psicoafectivos derivados del contacto en la enseñanza de deportes sociomotrices de colaboración-oposición. Alto rendimiento. Ciencia deportiva, entrenamiento y Fitness. III Congreso Nacional de Ciencias del Deporte. Pontevedra. http://altorendimiento.com/aversion-alcontacto-analisis-de-los-problemas-psicoafectivos-derivados-del-contacto-en-laensenanza-de-deportes-sociomotrices-decolaboracion-oposicion/

64. Salgado-López, J.I. (2014). As emoções como condicionante didático no ensino dos deportes sociomotores de colaboração oposição: Estudo dos problemas afetivos ligados ao contacto em Rugby, Andebol e Voleibol. Tesis doctoral, Universidade da Coruña, A Corunha. España. http://ruc.udc.es/dspace/handle/2183/13840

65. Salgado-López, J.I. (2020). Contacto y Emociones en la Educación Física y el Deporte. Factores didácticos para optimizar un aprendizaje inclusivo. Sevilla: Wanceulen.

66. Sicilia Camacho, A. (1999). El diario personal del alumnado como técnica de investigación en Educación Física. Apunts: Educació Física $i$ Esports, 58, 25-33. https://hemeroteca.revistaapunts.com/es/hemeroteca/?article $=474$ 


\section{Salgado-López, J.I., Sánchez-Molina, J.A.}

67. Sommer, R. (1974). Espacio y comportamiento individual. Madrid: Instituto de Estudios de Administración Local.

68. Torres Tobío, G. (1998). El conocimiento didáctico del contenido en la enseñanza de una técnica deportiva en Balonmano: El lanzamiento en salto con caída desde el extremo. La perspectiva de los expertos, entrenadores y jugadores. Tesis doctoral, Universidade da Coruña, A Corunha. España. https://dialnet.unirioja.es/servlet/tesis?codigo $=131654$

69. Troya Montañez, Y., Cuéllar Moreno, Mª.J. (2008). Tratamiento de la danza en el diseño curricular de educación secundaria para la Comunidad Autónoma de Canarias. En: Actas al IV Congreso Internacional y XXV Nacional de Educación Física. Cordoba.
70. Turrán Eguren, N. (2011). Problemas psicoafectivos derivados del contacto corporal. Revista Arista Digital, (15), 8-40. http://www.afapna.es/web/aristadigital/

71. Usero Martín, F. (1993). Rugby. Entrenamiento y Juego. Madrid: Campomanes.

72. Vázquez Navarrete, $M^{\mathrm{a}}$.L., Ferreira de Silva, $M^{a}$.R. (2006). Tema 5. Análisis de los datos cualitativos. En: $M^{\mathrm{a}}$.L. Vázquez Navarrete (coord.). Introducción a las técnicas cualitativas de investigación aplicadas a la salud, 129-145. Barcelona: Universitat Autònoma de Barcelona. Servei de Publicacions.

https://bibliotecadigital.univalle.edu.co/bitstr eam/handle/10893/18611/Intro_a_las_tecnica s_c.pdf?sequence $=1 \&$ is Allowed $=\mathrm{y}$ 